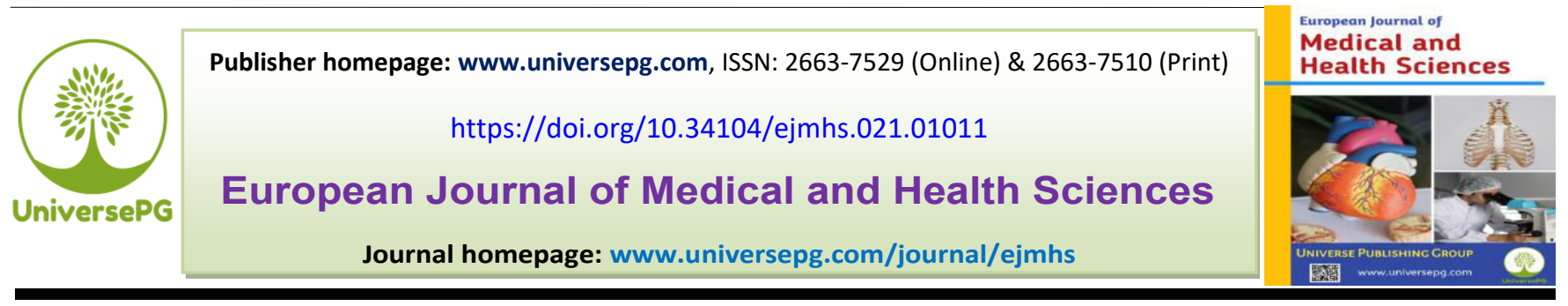

\title{
Causes and Complications of Cesarean Section Delivery among Women in Cox's Bazaar, Bangladesh
}

\author{
Zaziratul Zannat ${ }^{1}$, Zamiatul Zannath ${ }^{2}$, Md. Raisul Islam³, Nazmul Alam ${ }^{1}$, and Mohammad Manir \\ Hossain Mollah ${ }^{4}$
}

${ }^{1}$ Dept. of Public Health, Asian University for Women, Chittagong, Bangladesh; ${ }^{2}$ Dept. of Laws, National Law College, Chittagong, Bangladesh \& Department of HRM, Cox's Bazaar International University, Cox's Bazaar, Bangladesh; ${ }^{3}$ Dept. of Petroleum and Mining Engineering, Chittagong University of Engineering and Technology (CUET), Chittagong, Bangladesh; ${ }^{4}$ Dept. of Bioinformatics and Public Health, Asian University for Women, Chittagong, Bangladesh.

*Correspondence: zaziratul.zannat@ post.auw.edu.bd

\begin{abstract}
Unnecessary cesarean section (CS) delivery is a major problem in Bangladesh and it is draining resources from both supply and demand sides. Many women do their cesarean delivery because of indicated causes in pregnancy, fear of unbearable labor pain, thinking about the safety of child, etc. which leads to many unwanted complications. The aim of this research was to investigate the causes and preferences of cesarean delivery and to characterize the outcomes after cesarean section delivery. This cross-sectional study was conducted by using a semi-structured questionnaire among women who delivered in selected hospitals in Cox's Bazaar, Bangladesh. The total sample size number was 273 women with a mean age of 26.72 years. In this study the key reasons found for doing CS delivery were mother's age, occupation, higher education, previous cesarean, doctor's recommendation, fear of normal delivery and concern about baby's health. Results showed that $48.7 \%$ women faced complications and 50.3\% participants didn't face any complication after CS delivery. The most frequent complications were pus, $22 \%$ and obesity, $13.9 \%$ among the participants and breakdown of membrane, $28.2 \%$, excess bleeding, $19.4 \%$ extreme pain, $19 \%$ and prolonged labor, $18.3 \%$ were found as the main causes indicated by the doctors for cesarean delivery. The prevalence of CS found much higher than the anticipation of WHO. The Causes of cesarean delivery lead to the complications with various factors which effects women health directly and indirectly. It is necessary to reduce the rate by making the mothers aware of the risks of cesarean delivery and providing training workshops as well to overcome the fear of normal delivery.
\end{abstract}

Keywords: Cesarean section (CS) delivery, Causes, Cox's Bazaar, Complications, Perception, and Prevalence.

\section{INTRODUCTION:}

Cesarean section delivery has become very common surgical procedure in the world including in Bangladesh. Cesarean section is a surgical procedure, use for childbirth when vaginal delivery can't be performed. It is suggested to save the life of mother and baby in case of maternal complications during pregnancy. Before

UniversePG I www.universepg.com maternal and child mortality rate was high. Every day there are hundreds of maternal deaths reports due to complications of pregnancy (Carlo and Travers, 2016). Now the mortality rate has significant decrease. The ratio was 322 in 1998 to 2001 and 194 in 2007 to 2010 by considered as annual average rate of $5.6 \%$ decrease. Now it dropped to $14.1 \%$ from 2010 to $13.1 \%$ in 2016 (Arifeen et al., 2015; Sabnom and Islam, 2013). 
With the improvement of technology, surgery delivery came as a new invention of science as a life savior for most of the women. Home delivery by the unskilled nurse has been decreased with the modern devising. Studies figure out that over the past few years, child birth became too "medicalized" because of some nonobstetrical factors rather than obstetrical factors. These factors point out the concern for mother's health and influence the families (Bruekens, 2001; Khanday, 3013). Nowadays the unnecessary CS delivery is high in Bangladesh. The overuse of technology in medical sector is one specific reason behind this increasing rate. According to the report, the percentage of CS delivery is increased up to $51 \%$ which can correlate with the term, epidemic of over-medicalization of maternal health (Hasan, 2019; Bruekens, 2001). With the unnecessary numbers of CS delivery, women are also facing some unwanted complications. This study will explore the causes and also investigate the risk factors of complications associated with different factors.

Cesarean section delivery is now a controversial affair worldwide. The alarming rate of CS is actually surprising as it is high than the recommendation by WHO (2015). The rate has increased $6.7 \%$ to $19.1 \%$ from 1990 to 2014 all over the country. The less develop countries showed $14.6 \%$ absolute increase in CS delivery where developed and least developed countries showed rose by $12.7 \%$ and $4.2 \%$ (Betran et al., 2016). $60 \%$ of all births take place in low income countries on the contrary only $37.5 \%$ of births come off in middleand high-income countries but mostly the middle- and high-income countries give rise to CS rate globally. As per the estimation, among all 18.5 million annually performed CS deliveries, among that one-third are unnecessary and without any medical indications (Aminu et al., 2014). In Bangladesh the unnecessary $\mathrm{CS}$ rate is also high. According to the report, 7.7 out of 10 births are unnecessary. Overall, 860,000 unnecessary operations have been conducted last year in Bangladesh. But the women who really need of CS delivery they couldn't afford or access it while childbirth (Gibbons et al., 2010; Maswood, 2019). The trend of CS delivery among Bangladeshi women is increasing day by day. With globalization and advanced technology, the medical facilities have improved

UniversePG I www.universepg.com almost in every urban areas of Bangladesh. The basic emergency obstetric care services were introduced in public health care sector by the Ministry of Health and Family Welfare (MOH\&FW). These policies have improved the maternal and infant mortality rate as well as morbidities. However, this improved health care led to CS deliveries following by unintended complications (Rahman et al., 2014). Now women get better antenatal care during their pregnancy. In developing countries, the demand of CS delivery is increasing with the economic and educational advancement. Educated women are more likely to do Cesarean Section delivery to avoid labor pain.

Also, other factors such as infertility, modern reproductive techniques, and increased risk factors, age of women, psychology and biological safety for offspring leads women towards cesarean section deliver (Khawaja et al., 2007; Radha et al., 2015; Weaver et $a l$., 2007). Having lack of medical knowledge and misconception about vaginal delivery, works as an important and main factor for CS delivery (Azami et $a l ., 2014)$. It is true that mortality rate has been decrease after the invention of CS delivery but the natural childbirth is beneficial than operational one. Fear of labor pain impels women to do CS delivery. According to report, women who have already done CS delivery said normal delivery is more painful than CS (Ajeet et al., 2011). Psychological, physical and other related factors are associated with attitudes of labor pain which influence the decision of mode of delivery (Zakeri et al., 2015). Risk of dying during delivery or delivery related issues among women is 100 times higher in Bangladesh than any other developed countries. As a result, $75 \%$ babies die within the first week after their mother's death (Kamal, 2003).

In Bangladesh, almost $60 \%$ of childbirths take place at clinic and $65 \%$ of those deliveries are C-sections (Doucleff, 2018). Only 33\% of institutional deliveries has been done through CS in 2000 but it rise up to 63\% in 2014 (Haider, 2018). The rate of deliveries is higher in private hospitals $(86.2 \%)$ than the public hospitals (29.9\%). According to research, private hospitals get financial benefits from external agents for performing CS delivery (Aminu et al., 2014). Still mostly people prefer to do delivery in private hospitals than in public 
because of their better service quality though the cost is high but the outcome was found better in public hospitals (Andaleeb, 2000; Sabnom and Islam, 2013). Delivery cost also depends on the mode of delivery.

Nine out of ten women favoring vaginal delivery prefers CS delivery if the costing is same for both procedure (Ajeet et al., 2011). According to the report of 2010, about $10.3 \%$ of Total Health Expenditure (THE) was due to delivery costs from where $6.9 \%$ caused by CS deliveries (Haider, 2018). People often receive treatments and other facilities lately due to the cost. In Bangladesh, $49.6 \%$ population lives on less than US\$1.25 per day and $40 \%$ of the population lives below the poverty line (Klugman, 2010). Still people are doing CS deliveries as their perception is CS delivery can save mothers and child's birth without any complications even though for some people it is hard to afford. There are insufficient data on women's preferences for delivery mode, causes and factors associated with complications through CS delivery. The study aimed to examine the main causes and complications of cesarean section delivery specially highlighting women's perception of cesarean delivery in Cox's Bazaar, Bangladesh.

\section{MATERIALS AND METHODS:}

Study design: The study used cross sectional design to collect data from women who were 18 years or older and have done their CS delivery in the selected government hospital and clinical sites of Cox's Bazaar.

Sampling method: Purposive sampling method was used to selected women from hospitals and clinics who have conducted CS delivery. Study sample size was calculated using $23 \%$ reported CS prevalence rates (NIPORT, 2016), 5\% absolute precision and 95\% confidence level. Using formula as below the desired sample size was calculated to be 272 .

$$
\mathrm{n}=\mathrm{Z} 21-\mathrm{a} / 2 \mathrm{p}(1-\mathrm{p}) / \mathrm{d} 2
$$

Data collection: For data collection, a semi-structure questionnaire was used and divided into four parts. The first part contained socio demographic questions such as age, education, occupation, income etc. The second part of questionnaires had indication of CS delivery includes excess bleeding, respiratory problem, history of previous surgery, causes of cesarean, etc. UniversePG I www.universepg.com
Third part focused on the perception of women like fear of normal delivery, decision making process, affordability etc. Finally, the fourth and last part of the questionnaire was focus on complications of cesarean. Data was collected through face to face interviews from women willing to provide information about their delivery. The medium of the interview was Bengali. Data was collected with the help of research assistants. They had enough knowledge about the research topic. This research has been conducted under the supervision of Public Health Department advisors who are expertise in the field of research. The study was approved by the Ethical Review Committee (ERC) of Asian University for Women. The study maintained the privacy and confidentiality of the participants by using an identification number instead of name. Verbal consent was taken from the study participants. Before taking the consent the goal of the study was explained to the participants. They were given the chance to ask any questions regarding to the research if they have any. The participants also had the freedom to withdraw from the research any time they wanted.

Data analysis: For data analysis SPSS software version 23 and Microsoft excel was used. A descripttive analysis was executed to understand the distribution of socio demographic characteristics, decision making process, causes and risk factors of complications for data analysis. Chi-square, t-test and binary regression analyses were done to determine the relationship of the variables with the specific objecttives to set forward this study.

\section{RESULTS:}

In total 273 women were included in the study. The age of the study participants ranged from 18-40 years with the mean age of 25.48 years. Among them $48 \%$ of the respondents have 45 "'-5 height and relatively fewer percentages (14.3\%) was observed in 55- 57. 56.4\% women weight between $51-60 \mathrm{~kg}$. $42.1 \%$ women said they had bachelor or above level education and 52.4\% received education till higher secondary and 5.5\% women received no education. Among the participants, $24.9 \%$ worked for paid job, 59\% women were housewife and $16.1 \%$ women were regular student. Regarding their husband's occupation, $62 \%$ worked as a government employee, $33 \%$ did private employee, 
9.5\% were day laborer, $31.1 \%$ were businessman, $2.1 \%$ were farmer and $1.5 \%$ were transport workers. About $30.8 \%$ women have $15-35$ thousand income in their family, $29.7 \%$ have $36-55$ thousand income, $9.5 \%$ earn 56-85 thousand and 30\% participants didn't answer the question.

Table 1: Socio demographic distribution of the respondents $(\mathrm{N}=273)$.

\begin{tabular}{|l|c|c|}
\hline Variables & Frequency & Percentage \\
\hline Age in years & \multicolumn{2}{|c|}{} \\
18-24 year & 107 & 39.2 \\
25-30 year & 142 & 52.0 \\
31-40 year & 24 & 8.8 \\
\hline Mean age, std. deviation & \multicolumn{2}{|c|}{$25.48,3.83$} \\
\hline Height & \multicolumn{2}{|c|}{} \\
4'5',-5' feet & 131 & 48 \\
5'1',-5'4', feet & 103 & 37.7 \\
5'5', 5'7' feet & 39 & 14.3 \\
\hline Weight & & \\
40-50 kg & 99 & 36.3 \\
51-60 kg & 154 & 56.4 \\
61-70 kg & 20 & 7.3 \\
\hline Education & 15 & \\
Illiterate & 143 & 5.5 \\
Higher Secondary & 115 & 52.4 \\
B.A and above & & \\
\hline Occupation & 68 & 24.9 \\
Service Holder & 161 & 59.0 \\
Housewife & 44 & 16.1 \\
Student & & \\
\hline Husband Occupation & 62 & 22.7 \\
Government employee & 90 & 33.0 \\
Private employee & 26 & 9.5 \\
Day labor & 85 & 31.1 \\
Business & 6 & 2.1 \\
Farmer & 4 & 1.5 \\
Transport workers & & \\
\hline Monthly Income & 84 & 30.8 \\
15- 35 thousand & 82 & 29.7 \\
36- 55 thousand & & 30.5 \\
56- 85 thousand & & \\
No answer & & \\
\hline & & \\
\hline
\end{tabular}

Obstetric and non- obstetric medical causes of CS delivery: The set of factors affecting cesarean due to medical reasons has shown in Fig 1. Some of the medical factors among the reasons studied in this research are previous cesarean $(27.30 \%)$, depression $(45.40 \%)$, prolonged labor $(29.30 \%)$, respiratory $(47.30 \%)$ and multiple pregnancies $(2.60 \%)$ are the main medical reasons for cesarean delivery. Fig $\mathbf{2}$, UniversePG I www.universepg.com includes doctor's recommendation $(61.20 \%)$, fear of normal delivery $(63.40 \%)$, baby's safety $(95.20 \%)$, own decision $(38.80 \%)$ and affordability (48.0\%).

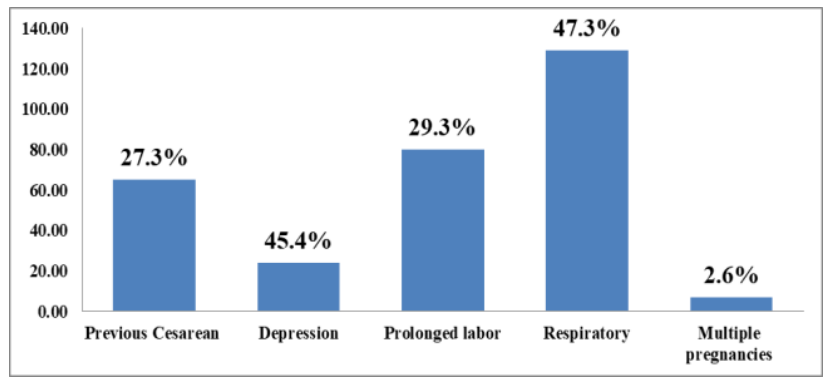

Fig 1: Obstetric-medical causes of cesarean section.

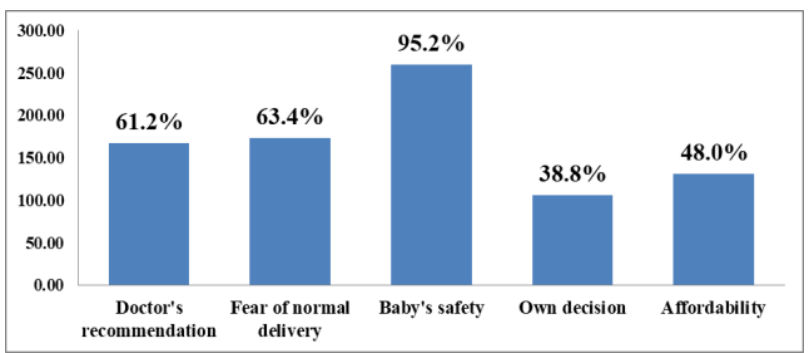

Fig 2: Non obstetric-medical causes of cesarean section.

Percentages of causes leading to CS delivery: Fig 3 shows the frequency of causes which led to CS delivery. Among the participants $18.30 \%$ faced prolonged labor, $28.20 \%$ had breakdown of membrane, $19.40 \%$ had excess bleeding, $19 \%$ had extreme pain, $11.70 \%$ respondents crossed the delivery date, $1.80 \%$ said their baby's size was too large, $1.50 \%$ respondents had fetal distress.

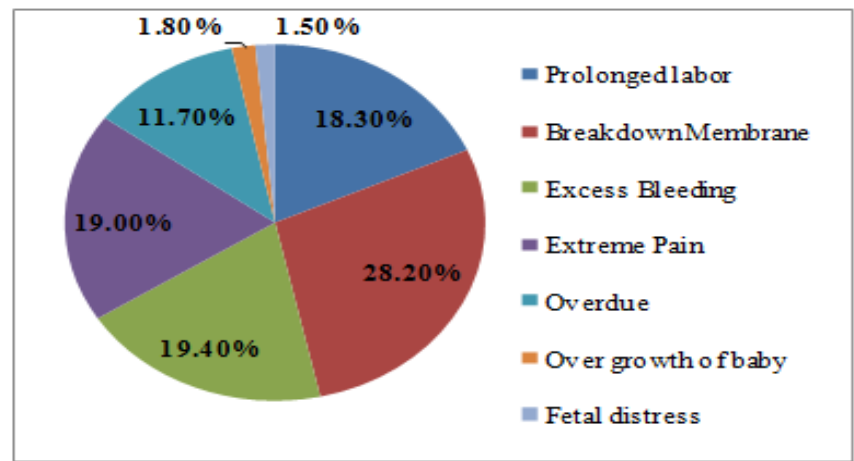

Fig 3: Causes of CS delivery.

Regression analysis: In binary logistic regression, education of the participants was found to as a significant predictor of CS delivery. Women with higher secondary education and no education were less likely to take decision for their CS delivery compared 
with B.A and above education. The history of patient's previous surgery also shows significant result which means this factor drive them to take decision for CS delivery. Besides, the participant's medical history of having respiratory showed significance and was found to have association with CS delivery. It was found that participants who reported having no respiratory was at 3.44 times at risk of having CS delivery than who had respiratory and when adjusted the risk of doing CS delivery was 4.90 times among the participants with no respiratory problem. However, It was seen that the risk of doing CS delivery was 0.16 times (CI: .09 - .29, pvalue: .000) greater among ones who have fear of normal delivery. When the adjusted risk increased to 0.58 times but didn't show significance. Same thing happened with age (25-30 years), fear of normal delivery depression and number of children. Other variables such as weight, education didn't show any significance in the test.

Table 2: Binary logistic regression analysis of factors associated with decision making of CS delivery.

\begin{tabular}{|c|c|c|c|c|}
\hline Variables & UOR $(95 \%$ of CI) & p-value & $\operatorname{AOR}(95 \%$ of CI $)$ & p-value \\
\hline $\begin{array}{l}\text { Age } \\
18-24 \text { year } \\
25-30 \text { year } \\
31-40 \text { year }\end{array}$ & $\begin{array}{l}-\quad \text { Ref } \\
0.29(0.11-0.75) \\
1.21(0.47-3.16)\end{array}$ & $\begin{array}{l}0.011 \\
0.694\end{array}$ & $\begin{array}{l}- \text { Ref } \\
1.26(0.32-4.92) \\
4.28(1.14-16.03)\end{array}$ & $\begin{array}{c}0.736 \\
0.031\end{array}$ \\
\hline $\begin{array}{l}\text { Weight } \\
40-50 \mathrm{~kg} \\
51-60 \mathrm{~kg} \\
61-70 \mathrm{~kg}\end{array}$ & $\begin{array}{l}-\quad \text { Ref } \\
0.22(0.061-0.80) \\
0.28(0.08-1.01)\end{array}$ & $\begin{array}{l}0.022 \\
0.052\end{array}$ & $\begin{array}{l}-\quad \text { Ref } \\
0.242(0.04-1.41) \\
0.486(0.08-2.69)\end{array}$ & $\begin{array}{l}0.115 \\
0.408\end{array}$ \\
\hline $\begin{array}{l}\text { Education } \\
\text { Illiterate } \\
\text { Higher Secondary } \\
\text { B.A and above }\end{array}$ & $\begin{array}{l}- \text { Ref } \\
1.71(0.550-5.32) \\
1.69(1.02-2.80)\end{array}$ & $\begin{array}{l}0.354 \\
0.041\end{array}$ & $\begin{array}{l}- \text { Ref } \\
1.16(0.35-3.82) \\
2.14(1.20-3.81)\end{array}$ & $\begin{array}{l}0.813 \\
0.010\end{array}$ \\
\hline $\begin{array}{l}\text { Number of children } \\
>2 \\
>2\end{array}$ & $\begin{array}{l}\text {-Ref } \\
0.07(0.02-0.31)\end{array}$ & 0.000 & $\begin{array}{l}-\quad \operatorname{Ref} \\
0.29(0.041-2.18)\end{array}$ & 0.233 \\
\hline $\begin{array}{l}\text { Respiratory problem } \\
\text { No } \\
\text { Yes }\end{array}$ & $\begin{array}{l}- \text { Ref } \\
3.44(2.04-5.78)\end{array}$ & 0.000 & $\begin{array}{l}- \text { Ref } \\
4.90(2.09-11.49)\end{array}$ & 0.000 \\
\hline $\begin{array}{l}\text { History of previous surgery } \\
\text { No } \\
\text { Yes }\end{array}$ & $\begin{array}{l}-\operatorname{Ref} \\
9.10(2.72-30.43)\end{array}$ & 0.000 & $\begin{array}{l}- \text { Ref } \\
7.26(1.48-35.55)\end{array}$ & 0.014 \\
\hline $\begin{array}{l}\text { Fear of normal delivery } \\
\text { No } \\
\text { Yes }\end{array}$ & $\begin{array}{l}-\quad \text { Ref } \\
0.16(0.09-0.29)\end{array}$ & 0.000 & $\begin{array}{l}-\quad \text { Ref } \\
0.58(0.178-1.89)\end{array}$ & 0.369 \\
\hline $\begin{array}{l}\text { Depression } \\
\text { No } \\
\text { Yes }\end{array}$ & $\begin{array}{l}- \text { Ref } \\
5.52(3.17-9.63)\end{array}$ & 0.000 & $\begin{array}{l}-\quad \text { Ref } \\
0.59(0.247-1.40)\end{array}$ & 0.232 \\
\hline
\end{tabular}

Percentages of complications faced after CS delivery: Fig 4 shows the percentages of complications among participants faced after CS delivery and the percentages are $22.0 \%$ pus, $8.80 \%$ incision, $13.90 \%$ obesity, $4.00 \%$ swelling and $51.30 \%$ with no complications.

Association of complications and risk factors: The relationship between types of complications and socio demographic variables has shown in Table 2. Women aged 18-24 years old are more likely to have pus $(50 \%)$ and become obese $(55.3 \%)$. Others aged bet-

UniversePG I www.universepg.com ween 25-30 years mostly suffers from incision (48\%) and swelling $(57.1 \%)$. Women aged with $31-40$ years old have less a case to become pregnant that is why the complications percentage seems less than other participants. Women who have 51-60 kg weight have more complications than others. Among the listed complications pus is the usual factor for service holders' women $(46.8 \%)$, housewife $(37.1 \%)$ and students $(16.1 \%)$. For incision complications house-wives $(60 \%)$ have more cases than service holders and students. Housewives (42.1\%) and students (39.5\%) 
become obese after delivery than service holders (18.4\%). $7.1 \%$ service holders, $78.6 \%$ housewives and $14.3 \%$ students have observed swelling in their CC cut. Women received education till higher secondary, B.A and above faces more complications than uneducated women.

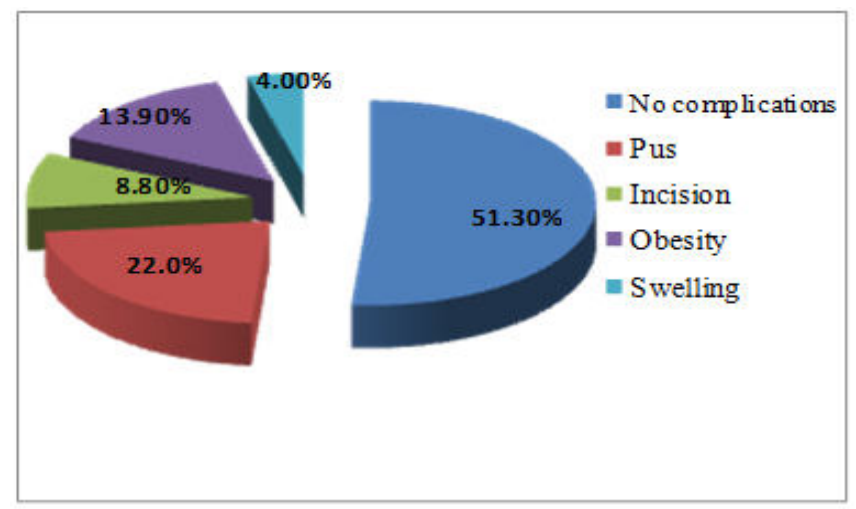

Fig 4: Level of complications after CS delivery.
From the chi-square test we found the p-value which shows age, weight and education have no relation with types of complications but occupation influence the types of complications after CS delivery. Among the listed complications pus is the usual factor for service holders' women $(46.8 \%)$, housewife $(37.1 \%)$ and students $(16.1 \%)$. For incision complications housewives $(60 \%)$ have more cases than service holders and students. Housewives (42.1\%) and students (39.5\%) become obese after delivery than service holders (18.4\%). $7.1 \%$ service holders, $78.6 \%$ housewives and $14.3 \%$ students have observed swelling in their $\mathrm{CC}$ cut. Women received education till higher secondary, B.A and above faces more complications than uneducated women. From the chi-square test we found the p-value which shows age, weight and education have no relation with types of complications but occupation influence the types of complications after CS delivery.

Table 3: Association between types of complications and socio demographic factors.

\begin{tabular}{|c|c|c|c|c|c|c|}
\hline Variables & \multicolumn{4}{|c|}{ Types of Complications } & Chi-square & p-value \\
\hline & Pus (\%) & Incision (\%) & Obesity (\%) & Swelling (\%) & & \\
\hline Age & & & & & 5.36 & .498 \\
\hline $\begin{array}{l}18-24 \text { year } \\
25-30 \text { year } \\
31-40 \text { year }\end{array}$ & $\begin{array}{l}31(50.0) \\
20(32.3) \\
11(17.7)\end{array}$ & $\begin{array}{l}10(40.0) \\
12(48.0) \\
3(12.0)\end{array}$ & $\begin{array}{l}21(55.3) \\
12(31.6) \\
5(13.2)\end{array}$ & $\begin{array}{l}5(35.7) \\
8(57.1) \\
1(7.1)\end{array}$ & & \\
\hline Weight & & & & & 10.27 & .114 \\
\hline $\begin{array}{l}40-50 \mathrm{~kg} \\
51-60 \mathrm{~kg} \\
61-70 \mathrm{~kg}\end{array}$ & $\begin{array}{l}20(32.3) \\
40(64.5) \\
2(3.2)\end{array}$ & $\begin{array}{l}10(40.0) \\
12(48.0) \\
3(12.0)\end{array}$ & $\begin{array}{l}11(28.9) \\
24(63.2) \\
3(7.9)\end{array}$ & $\begin{array}{l}7(50.0) \\
4(28.6) \\
3(21.4)\end{array}$ & & \\
\hline Occupation & & & & & 24.48 & .000 \\
\hline $\begin{array}{l}\text { Service Holder } \\
\text { Housewife } \\
\text { Student }\end{array}$ & $\begin{array}{l}29(46.8) \\
23(37.1) \\
10(16.1)\end{array}$ & $\begin{array}{l}3(12.0) \\
15(60.0) \\
7(28.0)\end{array}$ & $\begin{array}{l}7(18.4) \\
16(42.1) \\
15(39.5)\end{array}$ & $\begin{array}{l}1(7.1) \\
11(78.6) \\
2(14.3)\end{array}$ & & \\
\hline Education & & & & & 12.08 & .060 \\
\hline $\begin{array}{l}\text { Illiterate } \\
\text { Higher Secondary } \\
\text { B.A and above }\end{array}$ & $\begin{array}{l}7(11.3) \\
33(53.2) \\
22(35.5)\end{array}$ & $\begin{array}{l}1(4.0) \\
13(52.0) \\
11(44.0)\end{array}$ & $\begin{array}{l}0(0.0) \\
14(36.8) \\
24(63.2)\end{array}$ & $\begin{array}{l}2(14.3) \\
8(57.1) \\
4(28.6)\end{array}$ & & \\
\hline
\end{tabular}

\section{Cesarean section delivery cost distribution: Figure}

5 summarizes the expenditure of CS delivery. Among the participants $52 \%$ spend $15-25$ thousand, $28.20 \%$ spend 26-35 thousand, 5.90\% spend 36-50 thousand and others around $13.90 \%$ participants didn't answer the question. The lowest amount is 15 thousand and 50 thousand is the highest cost of CS delivery. $49 \%$ participants could bear the cost because they had savings, $16.8 \%$ took loan and $34.1 \%$ could cover the cost from their salary.

UniversePG I www.universepg.com
Among the participants 52\% said they didn't have affordability to pay the cost of CS delivery but they hardly managed it and $48 \%$ said they didn't find any difficulties to pay or arrange money for CS delivery.

\section{DISCUSSION:}

This study was aimed to identify the causes and complications of CS delivery in Bangladesh. In this study, complications were reported by $48.7 \%$ of the women which is much higher compared to the study conducted 
in 2014 by Bangladesh Demographic and Health Survey with $23 \%$ prevalence rate (NIPORT, 2016).

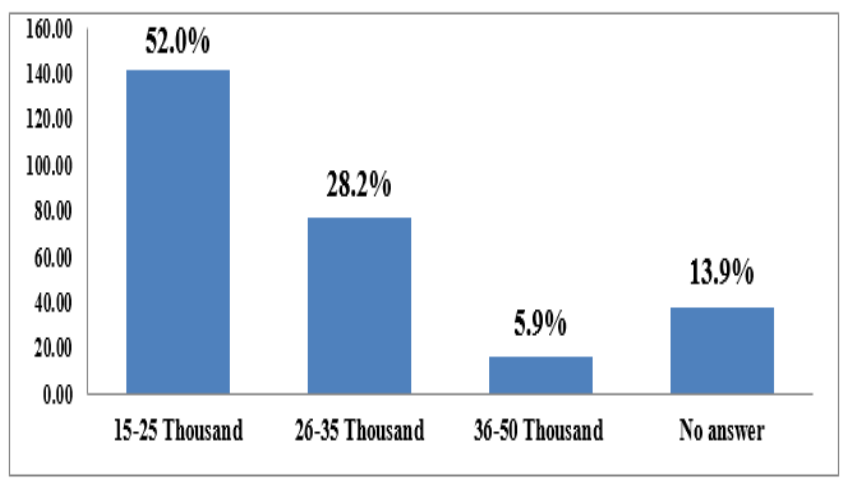

Fig 5: Approximate expenditure for doing cesarean section.

Table 4: Cost and affordability related to cesarean section delivery.

\begin{tabular}{|l|l|l|}
\hline Variables & Frequency & Percentage \\
\hline CS cost index & & \\
15-25 Thousand & 142 & 52 \\
26- 35 Thousand & 77 & 28.2 \\
36-50 Thousand & 16 & 5.9 \\
$\quad$ No answer & 38 & 13.9 \\
\hline Affordability & & \\
$\quad$ No & 142 & 52 \\
Yes & 131 & 48 \\
\hline Arrangement & & \\
Savings & 134 & 49.1 \\
Loan & 46 & 16.8 \\
Salary & 93 & 34.1 \\
\hline
\end{tabular}

The World Health Organization (WHO) recom-mends a C-section rate of between $10 \%$ and $15 \%$ of all births per country but the percentage found in this study is $50.9 \%$ which is much higher than the recommendation by WHO (WHO, 2015). It has been reported that now in Bangladesh the percentage has increased up to $51 \%$ due to unnecessary CS delivery (Save the Children, 2019). The recent data showed that, more than $60 \%$ of the world's nations have overused the CS procedure within 169 countries (Weule, 2018).

According to the CNN report, all over the region the prevalence of CS delivery is $4.1 \%$ in West and Central Africa, $6.2 \%$ in Eastern and Southern Africa, 29.6\% in the Middle East and North Africa, $18.1 \%$ in South Asia, 28.8\% in East Asia and the Pacific, $44.3 \%$ in
Latin America and Caribbean, 27.3\% in Eastern Europe and Central Asia, 32\% in North America, $26.9 \%$ in Western Europe (Howard, 2018). The percentage of CS delivery varied differently in different regions for various reasons such as cultural, educational and economic differences.

The result of this study highlighted that depression and respiratory problem were the prime reasons for obstetric medical factors. Others reasons included previous cesarean delivery, prolonged labor, multiple pregnancies were among the least common medical factors. On the other hand, non-obstetric causes like baby's safety were the priority for all the parents which led to CS delivery. It was strongly perceived by the participants that CS delivery would save the life and health of the child. But CS delivery caused complications for neonatal as well. Studies showed that, respiratory disorder was higher among the newborn with cesarean delivery. Not only preterm infants but also near-term babies suffer from severe respiratory distress syndrome caused by surfactant deficiency (Roth-Kleiner et al., 2015). However, the expert recommends that without any emergency and obstetrical indications, no cesarean should perform for the sake of newborns health (Rafiei et al., 2018).

For conducting CS delivery doctors justified at least one cause under certain complicated problems during delivery time. According to BDHS- 2014 report, due to avoid labor pain (3.2\%), and in the cases of mal presentation $(41.5 \%)$, premature baby $(1.7 \%)$, cord prolapsed $(2.6 \%)$, multiple births $(0.2 \%)$, failure to progress in labor $(21.1 \%)$, preeclampsia $(2.9 \%)$, diabetes $(0.5 \%)$, less pressure on baby's brain $(9.7 \%)$, convenience $(5.8 \%)$ and other complications $(38.6 \%)$ doctors mentions proposed to undergo CS delivery (Hasan et al., 2019). However, without any complications also some CS deliveries were performed.

Higher educated but housewives aged between 18-24 years were more likely to do CS delivery. The service holder women mostly take their own decision but housewives considered their doctors recommendation. Similarly, in other studies, it's alleged that educated and pregnant woman mostly afraid of labor pain and other complications of vaginal delivery. Women with higher education, highest socioeconomic status, age, 
have access to facilities and mostly deliver a baby boy underwent CS delivery (Khan et al., 2018; Manyeh et al., 2018; Mia et al., 2019). But the individual contribution factors were also important to CS delivery. These factors would help us to figure out the consequences of CS delivery in order to make awareness and promote health policy.

Women conducted cesarean delivery for one or two times suffers from pus, incision, obesity, swelling more than the women who did normal delivery for their first child. Percentage of becoming obese is higher than other complications among them. The complications were higher among the higher educated women aged 18-24 years old. Surprisingly, the housewives face more complications than service holder women. The percentage of pus $(46.8 \%)$ observed higher than the other complications among the service holders. This study also found out that $51.3 \%$ women faced no complications after CS delivery.

Family income was also influenced CS delivery. From the study, it has been found out that, economically affluent participants were more likely to do CS delivery than others. Those who couldn't afford they spent their salary, took loan or used their savings. Most of the participants reported costing 15-25 thousand taka, while only $5.90 \%$ participants mentioned they spent 36-50 thousand for CS delivery. Perhaps, they had better treatment facilities in private hospitals during delivery. It is assumed that the socio demographic and economic factors were associated with the increase rate of cesarean delivery (Vieira et al., 2015).

Women's life style affected by the CS delivery because complications were related to both physical and psychological concerns. This research focused on medical complications after CS delivery not the others factors. But other studies indicated that after cesarean birth women faces additional stress, less satisfaction with birth experience, guilt, anxiety, and loss of selfesteem (Miovech et al., 2013). Maternal care was really important to avoid the complications of CS delivery. The study limitations included having possibility of recall bias in reporting the reasons of CS delivery properly and also lack of generalizability because the study was conducted only in one city of Bangladesh.

UniversePG I www.universepg.com

\section{CONCLUSION:}

The findings of this study showed that those who did CS delivery for the first time were more likely to do it for the second time because they thought they were not capable to do vaginal delivery anymore. Also, the women who did normal delivery for their first child had specific health issues mentioned by doctors to perform cesarean section for their second delivery or next child. Women's age, education, and occupation significantly predicted decision making of CS delivery, which a number of health complications to mothers. The aver-age cost of CS delivery was not affordable for most families yet people are doing CS delivery for the sake of their baby's safety and doctor's suggestion. The study recommends generalized awareness raising campaign targeting prospective mothers and couples to use antenatal check-up during pregnancy and to increase knowledge about pregnancy danger signs needing emergency obstetric care. Professional integrity and ethics training should be strengthening for health care providers to exercise medically oriented protocol in recommending CS delivery.

\section{ACKNOWLEDGEMENT:}

I am grateful to all the participants who took part in the study. I am deeply grateful to AUW for funding this project and thank the research assistants for help during data collection process.

\section{CONFLICTS OF INTEREST:}

The author(s) declare there is no conflict of interest.

\section{REFERENCES:}

1. Ajeet, Saoji; Nayse, Jaydeep; Kasturwar, Nandkishore, Relwani, Nisha, (2011). Women's Knowledge, perceptions and Potential Demand towards Cesarean Section. National J. of Community Medicine, 2(2), 1-5. www.njcmindia.org/uploads/2-2 244248.pdf

2. Aminu, M., Utz, B., Halim, A. et al. (2014). Reasons for performing a caesarean section in public hospitals in rural Bangladesh. BMC Pregnancy Child birth, 14, 130. https://doi.org/10.1186/1471-2393-14-130 
3. Andaleeb, Syed, (2000). Public and private hospitals in Bangladesh: Service quality and predictors of hospital choice. Health policy and planning, 15(1), 95-102.

https://doi.org/10.1093/heapol/15.1.95

4. Arifeen, Shams \& Hill, Kenneth \& Ahsan, Karar \& Jamil, Kanta \& Nahar, Quamrun \& Streatfield, Peter (2015). Maternal Mortality in Bangladesh. Obstetrical \& Gynecological Survey, 70,74-75.

https://doi.org/10.1097/01.ogx.0000461895.7873 $\underline{4.18}$

5. Azami, Aghdash S., Ghojazadeh, M., Dehdilani, N., Mohammadi, M., \& Asl Amin Abad, R. (2014). Prevalence and Causes of Cesarean Section in Iran: Systematic Review and MetaAnalysis. Iranian journal of public health, 43(5), 545-555.

https://pubmed.ncbi.nlm.nih.gov/26060756/

6. Bashar MA, Haque AKMR, and Rahman R. (2020). Prevalence of anaemia among pregnant women in a rural area of Bangladesh: impact of socio-economic factors, food intake and micronutrient supplementation. Am. J. Pure Appl. Sci., 2(1), 1-7. https://doi.org/10.34104/ajpab.0200107

7. Betran, A. P., Ye, J., Moller, A. B., Zhang, J., Gulmezoglu, A. M., \& Torloni, M. R. (2016). The Increasing Trend in Caesarean Section Rates: Global, Regional and National Estimates: 1990-2014. PloS one, 11(2), e0148343. https://doi.org/10.1371/journal.pone.0148343

8. Bruekens, P. (2001). Over-medicalization of maternal care in developing countries. In Brouwere VD and Lerberghe WV (ed.). Safe Motherhood Strategies: A Review of the Evidence. Antwerp: ITG Press, 17, pp.1-5. www.researchgate.net/publication/242075892 O ver-medicalisation_of_Maternal_Care_in_De veloping_Countries

9. Carlo WA, Travers CP. (2016). Maternal and neonatal mortality: time to act, 2016. J Pediatr (Rio J), 92: 543-5.

http://www.scielo.br/scielo.php?script=sci_arttex t\&pid=S002175572016000700543

10. Doucleff, Michaeleen, (2018). Rate Of CSections Is Rising At An 'Alarming' Rate,
Report Says. National Public Radio. Retrieved from -

www.npr.org/sections/goatsandsoda/2018/10/12/ 656198429/rate-of-c-section-is-risingat-an-ala rming-rate

11. Gibbons,Luz; Belizan, Jose M., Jeremy A Lauer, Ana P Betran, Mario Merialdi and Fernando Althabe, (2010). The global numbers and costs of additionally needed and unnecessary caesarean sections performed per year: overuse as a barrier to universal coverage. World Health Organization (WHO). http://www.who.int/healthsystems/topics/financi ng/healthreport/30C-sectioncosts.pdf

12. Haider MR, Rahman MM, Moinuddin M, Rahman AE, Ahmed S, Khan MM. (2018) Ever increasing Caesarean section and its economic burden in Bangladesh. PLoS ONE, 13(12): pp.1-13. https://doi.org/10.1371/journal.pone.0208623

13. Hasan, F., Alam, M.M. \& Hossain, M.G. (2019). "Associated factors and their individual contributions to caesarean delivery among married women in Bangladesh: analysis of Bangladesh demographic and health survey data." BMC Pregnancy Child birth, 19(433), 1-9. https://doi.org/10.1186/s12884-019-2588-9

14. Hasan, Md. Kamrul (2019).C-sections up by $51 \%$ in Bangladesh in two years. Dhaka Tribune, Retrieved fromhttp://www.dhakatribune.com/bangladesh/nation /2019/06/21/csections-up-by-51-in-bangladeshsays-reprt

15. Howard, Jacqueline (2018). "C-section deliveries nearly doubled worldwide since 2000 , study finds." CNN Health. Retrieved fromhttps://edition.cnn.com/2018/10/11/health/csection\%20rates-study-parenting-without-bor ders-intl/index.html

16. Kamal S. M. (2013). Preference for institutional delivery and caesarean sections in Bangladesh. J. of health, population, and nutrition, 31(1), 96-109. https://doi.org/10.3329/jhpn.v31i1.14754

17. Khan, Nuruzzaman \& Islam, M. Mofizul \& Rahman, Mijanur. (2018). Inequality in 
utilization of cesarean delivery in Bangladesh: a decomposition analysis using nationally representative data. Public Health. 157,111120. https://doi.org/10.1016/j.puhe.2018.01.015

18. Khanday, Zulufkar Ahmad (2013). Review on Medicalisation: A critical appraisal with special reference to India, Intern. J. of Medical Sociology and Anthropology, 2(2), pp.66-75. www.academia.edu/6223034/Review on Medic alisation_A critical_appraisal_with special_refe rence_o_India

19. Khawaja M, M Al-Nsour and M Khawaja (2007). Trends in prevalence and determinants of caesarean delivery in Jordan: Evidence from three demographic and health surveys 19902002, World Health and Population, 9(4), 1728. https://doi.org/10.12927/whp.2007.19395

20. Klugman, Jeni (2010). The Real Wealth of Nations: Pathways to Human Development. UNDP-HDRO Human Development Report 2010-20th Anniversary Edition, pp.1-234 https://ssrn.com/abstract=2294686

21. Manyeh, A.K., Amu, A., Akpakli, D.E. et al. (2018). Socioeconomic and demographic factors associated with caesarean section delivery in Southern Ghana: evidence from INDEPTH Network member site. BMC Pregnancy Childbirth, 18(405), 1-9. https://doi.org/10.1186/s12884-018-2039-Z

22. Maswood, Manzur H (2019). Caesarean births boom in Bangladesh. New Age Bangladesh. www.newagebd.net/article/76766/caesareanbirths-boom-in-bangladesh

23. Miovech, S. M., Knapp, H., Borucki, L., Roncoli, M., Arnold, L., \& Brooten, D. (2013). Major concerns of women after cesarean delivery. Journal of obstetric, gynecologic, and neonatal nursing: JOGNN, 23(1), 1-11. https://doi.org/10.1111/j.1552-6909.1994.tb0 1850.x

24. Mia, Mohammad Nahid; Mohammad Zahirul Islam, Md Razib Chowdhury, Abdur Razzaque, Brian Chin, M. Shafiqur Rahman (2019). "Socio-demographic, health and institutional determinants of caesarean section among the poorest segment of the urban population: Evidence from selected slums in
Dhaka, Bangladesh.” SSM-Population Health, 8, 1-7. https://doi.org/10.1016/j.ssmph.2019.100415

25. National Institute of Population Research and Training (NIPORT), Mitra and Associates, and ICF International. 2016. Bangladesh Demographic and Health Survey 2014. Dhaka, Bangladesh. Retrieve from https://dhsprogram.com/pubs/pdf/FR311/FR311. pdf

26. Radha, K.; Devi, G. Prameela; R, V. Manjula; P. A. Chandrasekharan, (2015). Study On Rising Trends Of Caesarean Section (CSection): A Bio-Sociological Effect. J. of Dental and Medical Sciences (IOSR-JDMS), 10-13. https://doi.org/10.9790/0853-14821013

27. Rafiei, M., Saei Ghare, M., Akbari, M., Kiani, F., Sayehmiri, F., Sayehmiri, K., \& Vafaee, R. (2018). Prevalence, causes, and complications of cesarean delivery in Iran: A systematic review and meta-analysis. International $J$. of reproductive biomedicine (Yazd, Iran), 16(4), 221-234.

https://pubmed.ncbi.nlm.nih.gov/29942930/

28. Rahman MM, Haider MR, Moinuddin M, Rahman AE, Ahmed S, Khan MM. (2018). Determinants of caesarean section in Bangladesh: Cross-sectional analysis of Bangladesh Demographic and Health Survey 2014 Data. PLOS ONE, 13(9): e0202879.

https://doi.org/10.1371/journal.pone.0202879

29. Roth-Kleiner, Matthias \& Wagner, Bendicht \& Bachmann, Denis \& Pfenninger, Jurg. (2003). Respiratory distress syndrome in near term babies after C-section. Swiss medical weekly, 133, 283-288.

30. Sabnom, R., \& Islam, M. (2013). Cost and outcome of caesarean section in a public and private hospital in Dhaka city. Bangladesh Journal of Medical Science, 12(3), 276-281, https://doi.org/10.3329/bjms.v12i3.15424

31. Save the Children, (2019). Bangladesh: 51 percent Increase in "Unnecessary" C-Section in Two Years, Save the Children 100 years. www.savethechildren.net/news/bangladesh-51cent-increase-\%E2\%80\%9Cunnecessary\%E2\% $\underline{80 \% 9 \mathrm{D}-c-s e c t i o n s-t w o-y e a r s}$ 
32. Sujan, Moudud Ahmmed (2019). Maternal causes behind $13 \mathrm{pc}$ deaths. The Daily Star, Retrieved fromwww.thedailystar.net/backpage/bangladesh-mat ernal-mortality-rate-isthirteen-percent-surv ey$\underline{\text { says- } 759075}$

33. Vieira, G. O., Fernandes, L. G., de Oliveira, N. F., Silva, L. R., \& Vieira, T. (2015). Factors associated with cesarean delivery in public and private hospitals in a city of northeastern Brazil: a cross-sectional study. BMC pregnancy and childbirth, 15, 132.

https://doi.org/10.1186/s12884-015-0570-8

34. Weaver, Jane. J., Statham, H. and Richards, M. (2007). Are There "Unnecessary" Cesarean Sections? Perceptions of Women and Obstetricians about Cesarean Sections for Nonclinical Indications. Wiley Online Library, 34: 32-41.

https://doi.org/10.1111/j.1523\%20536X.2006.00 144.X
35. Weule, Genelle (2018). "The countries where more than half of babies are delivered via caesarean." Science News. Retrieved fromwww.abc.net.au/news/science/2018-10- 15/coun tries-where-more-than-half-babies-born-by-csection/10370302

36. WHO Statement on Caesarean Section Rates (2015). Department of Reproductive Health and Research: World Health Organization (WHO).

https://www.who.int/mediacentre/news/release s/2015/caesarean-sections/en/

37. Zakeri, Hamidi M., Latifnejad Roudsari, R., \& Merghati Khoei, E. (2015). Vaginal Delivery vs. Cesarean Section: A Focused Ethnographic Study of Women's Perceptions in The North of Iran. International J. of community based nursing and midwifery, 3(1), 39-50. https://pubmed.ncbi.nlm.nih.gov/25553333/

Citation: Zannat Z., Zannath Z., Islam MR., Alam N., and Mollah MH. (2021). Causes and complications of cesarean section delivery among women in Cox's Bazaar, Bangladesh, Eur. J. Med. Health Sci., 3(1), 1-11. https://doi.org/10.34104/ejmhs.021.01011 (c) 